\title{
SOMBRAS EN EL ILUSTRADO ANTONIO VALCÁRCEL, CONDE DE LUMIARES
}

\author{
Enrique Giménez López \\ Universidad de Alicante
}

\section{RESUMEN}

Antonio Valcárcel Pío de Saboya, Conde de Lumiares, fue un pionero de los estudios arqueológicos en España y llegó a formar parte de la Junta Central que se enfrentó en 1808 a Napoleón. Pero a fines del siglo XVIII se vio envuelto en un asunto judicial que puso de manifiesto el clima conflictivo de la sociedad rural alicantina, y su modo de vida poco ejemplar.

Palabras clave: Siglo XVIII; Alicante; Sant Joan d'Alacant; Arqueología; vida rural; conflictos criminales; Audiencia de Valencia.

\section{ABSTRACT}

Shadowns in the Illustrated Antonio Valcárcel, Count of Lumiares

Antonio Valcárcel Pío de Saboya, Count of Lumiare, was a pioneer of archaeological studies in Spain and was part of the Junta Central faced Napoleon in 1808. But in the late eighteenth century was involved in a court case that highlighted the troubled climate of society Alicante rural and their lifestyles.

Keywords: Century XVIII; Alicante; Sant Joan d'Alicante; Archeology; Rural life; criminal conflict; Court of Valencia

En abril de 1789 se celebró en Alicante la proclamación de Carlos IV con sendas representaciones de la ópera de Paisiello «El Barbero de Sevilla» en la casa paterna del conde de Lumiares, levantada a mediados del siglo XVIII por Antonio Valcárcel Pérez Pastor, natural de Hellín, quien era Caballero de la Orden de Santiago y regidor de Madrid. En 1747 se había casado con María Isabel Pío 
de Saboya, Marquesa de Castelrodrigo ${ }^{1}$, un título con grandeza de España, que llevaba aparejado para uso del primogénito el de Conde de Lumiares.

El matrimonio llegó a Alicante en torno a 1747. Lumiares nació en marzo de 1748, según figura en la partida bautismal que se conserva en el archivo parroquial de Santa María².

Ya en 1751 la familia Valcárcel aparecía como residente en la calle Postiguet, la actual calle Gravina. En el Vecindario de 1754, primer censo que se efectuó en Alicante ${ }^{3}$-único que especifica el número de habitantes por vivienda-, aparece el Palacio de los Valcárcel como domicilio del matrimonio, su hijo el conde de Lumiares, dos de sus hermanas, y 11 sirvientes, entre mayordomo, lacayos y domésticas.

El conde de Lumiares es uno de los alicantinos más ilustres que ha dado la ciudad. Su labor cultural se enmarca en la Ilustración española y en los orígenes de la arqueología y la epigrafía latina ${ }^{4}$. Ya en 1773, con veinticinco años, era uno de los pioneros de la numismática española, pues acababa de publicar en Valencia el libro «Medallas de las colonias, municipios y pueblos antiguos de España hasta hoy no publicadas», donde daba a conocer el monetario romano que había ido coleccionando. Un año después inició uno de sus muchos recorridos por tierras valencianas en busca de inscripciones latinas, registrando las que encontró en Tárbena, Ondara, Murla y Villajoyosa, entre otros lugares. Fue correspondiente de la Academia de la Historia y miembro de las de Buenas Letras de Barcelona y San Carlos de Valencia, y emprendió excavaciones arqueológicas en Elche, Alicante y Sagunto. En 1780 publicó «Lucentum, hoy la ciudad de Alicante», donde daba cuenta e incluía láminas de las inscripciones, estatuas, medallas, lucernas y cerámicas varias encontradas en las excavaciones que había efectuado en la Albufereta. Complementaba este libro el que dos años antes había dedicado a los «Barros saguntinos» y que constituye uno de los primeros trabajos sobre la cerámica terra sigilata hispánica ${ }^{5}$. No obstante, la gran

1. Era hija del militar de origen milanés Francisco Pío de Saboya Moura, marqués de Castelrodrigo, que en mayo de 1715 fue nombrado por Felipe V Capitán General de Cataluña. Vid. Giménez LóPEZ, Enrique: «El primer Capitán General de Cataluña, Marqués de Castelrodrigo (17151721) y el control del austracismo», en Fernández Albaladejo, Pablo: Los Borbones. Dinastía y memoria de Nación en la España del siglo XVIII, Madrid 2001, pp. 401-420.

2. Abascal, Juan Manuel, DIE, Rosario y Cebrián, Rosario: Antonio Valcácel Pío de Saboya, Conde de Lumiares (1748-1808). Apuntes biográficos y escritos inéditos, Madrid 2009, p. 30 y ss.

3. A. M. A. Armario 7 Libro 8: Vecindario de todas las personas residentes en esta Ciudad y término de Alicante, con expresión de los nombres, edad, y número de que se compone cada familia.

4. Mestre Sanchis, Antonio: Humanismo y crítica en los ilustrados alicantinos, Alicante 1980, pp. 174-195.

5. Mora, Gloria: «Literatura anticuaria», en Aguilar Piñal, Francisco (ed.): Historia literaria de España en el siglo XVIII, Madrid 1996, pp. 883-914. 
obra de Lumiares fue «Inscripciones y antigüedades del Reino de Valencia», donde plasmaba las investigaciones realizadas a lo largo de treinta años, y que fue presentada en la Academia de la Historia en 1805, aunque no pudo publicarse hasta 1852, por iniciarse tres años después la Guerra de la Independencia.

Fueron tiempos recios aquellos de la primera década del siglo XIX, en los que Lumiares demostró su condición de patriota. Cuando se produjeron los sucesos de mayo de 1808, Antonio Valcárcel Pío de Saboya y Espínola de la Cerda encabezó la Junta local constituida en Alicante ${ }^{6}$, publicó bandos llamando a la resistencia de los alicantinos frente a los franceses, y formó parte de la Junta Suprema de Gobierno en Valencia para enfrentarse al invasor. La muerte le llegó en Aranjuez el 14 de noviembre de 1808 cuando acababa de constituirse la Junta Central, de la que era miembro destacado como representante del Reino de Valencia junto al conde de Contamina. Fue enterrado en el convento de San Pascual de Aranjuez. En la fachada del Ayuntamiento puede verse una lápida colocada en 1908 en la que figura como Hijo Ilustre de Alicante e Investigador experto en las antigüedades patrias ${ }^{7}$.

Pero en los años noventa el conde de Lumiares se vio envuelto en un turbio asunto del que judicialmente salió mal parado ${ }^{8}$. En 1793, al parecer por desavenencias conyugales, se encontraba avecindado en la localidad de San Juan, en plena huerta de Alicante, donde poseía tierras. San Juan estaba dividida en parcialidades, donde los pleitos por el agua de riego originaba frecuentes conflictos y acusaciones de que se cortaba el agua a ciertos propietarios en beneficio de otros. Uno de los bandos estaba encabezado por el hacendado Antonio Pastor, licenciado en derecho, y el otro por el bachiller José Llopis, que se profesaban gran enemistad. El conde de Lumiares apoyaba decididamente a Llopis, y lo manifestaba públicamente cuantas veces tenía ocasión, e incluso había rechazado cualquier trato con Pastor. La situación llegó a ser muy tensa cuando Llopis y Pastor accedieron, respectivamente, a los cargos de alcalde y síndico personero de San Juan, y Llopis ordenó detener a su rival por su negativa a acompañar a la corporación municipal en la procesión del Corpus.

Corrió el rumor por entonces de que Pastor había ofrecido 100 libras por asesinarlo. El 21 de julio de 1793 Lumiares informó de tal murmuración a la Sala del Crimen de la Audiencia de Valencia ${ }^{9}$, y solicitó que el tribunal comisionase

6. Moliner Prada, Antonio: «Las transformaciones políticas durante la Guerra en una ciudad no conquistada: Alicante (1808-1814), en Álvarez CAÑAs, María Luisa (dir.): La Guerra de la Independencia. Alicante (1808-1814), Alicante 2010, pp. 71-102.

7. MarTínez Morellá, Vicente: Lápidas conmemorativas en las vías públicas de Alicante, Alicante 1956.

8. Un resumen del caso en Abascal, Juan Manuel et alii: Op. Cit. pp. 54-59.

9. A. H. N. Consejos leg. 22.839 Representación del Conde de Lumiares a la Real Audiencia de Valencia, 21 de julio de 1793. 
a una persona de su confianza para que investigara su veracidad y adoptara las providencias más oportunas para asegurar su vida. El justicia de la vecina localidad de Muchamiel fue el encargado de realizar las primeras pesquisas ${ }^{10}$, tras las que procedió a la detención de Pastor el 16 de octubre de 1793 «por su atroz y desmesurado delito». Acto seguido, dictó el embargo de sus bienes, y su arresto, situación en que permaneció hasta marzo del siguiente año. Pastor respondió tachando a Lumiares de calumniador y pidió su libertad bajo fianza ${ }^{11}$, tras lo que el conde decidió acusarle de inducción al asesinato ${ }^{12}$. Cuando el 8 de marzo de 1794 fue puesto en libertad provisional, Pastor se trasladó a Valencia por temor a que el alcalde de Muchamiel, al que consideraba vinculado estrechamente a Lumiares, ordenara de nuevo su detención, y la Audiencia determinó que no saliese de Valencia hasta que se dictara sentencia.

Los testigos de Lumiares fueron tres: José Juan, alias El Romo, quien declaró que en 1793, cuando trabajaba de peón en un puente que construía Pastor frente a su casa, le dijo «que si le pegaba un carabinazo al conde de Lumiares le daría 100 libras, o toda su hacienda, y que no padecería su familia», una oferta que le fue reiterada unos días después; el segundo testigo era Juan Bautista Senia, quien afirmó que un vecino le había comentado que había escuchado a Pastor en conversación privada que ojala le cayese a Lumiares el campanario cuando pasase por la puerta de la iglesia de San Juan, y que «a él y a su familia se los llevase el diablo porque tenían al pueblo alborotado»; el tercero en testificar fue Constantino Terol, un jornalero a quien Pastor habría ofrecido «cuanto le pidiese» si mataba a Lumiares ${ }^{13}$.

Los vínculos familiares desempeñaban un importante papel en el ambiente enrarecido que se vivía en la población huertana de San Juan en aquellos días. Pastor, el acusado de instigación al crimen, era pariente del alcalde ordinario Francisco Poveda, casado con una prima hermana suya, y a quien asesoraba en muchas cuestiones relacionadas con la vida de la localidad. En ese año de 1793 el alcalde permitió «a la gente de humor del pueblo» la celebración del carnaval, y durante la fiesta de máscaras se escucharon algunos vivas a la Asamblea francesa, incidente que Lumiares puso en conocimiento de la Audiencia de Valencia por considerarlo sedicioso, ya que Luis XVI acababa de ser guillotinado. Comisionado el alcalde mayor de Biar por el tribunal valenciano para averiguar

10. A. H. N. Consejos leg. 22.839 Decreto de la Real Audiencia de Valencia dando comisión a la Justicia de Muchamiel, Valencia 30 de julio de 1793.

11. A. H. N. Consejos leg. 22.839 Declaración del Licenciado Antonio Pastor en 24 de octubre de 1793.

12. A. H. N. Consejos leg. 22.839 Acusación del Promotor Fiscal Francisco Muñoz en 4 de noviembre de 1793.

13. A. H. N. Consejos leg. 22.839 Información sumaria a instancia del Conde de Lumiares en 9 , 11 y 23 de agosto de 1793. 
lo sucedido, tomó la decisión de encarcelar al alcalde Poveda, lo que provocó un gran disgusto en Pastor, quien consideró que Lumiares había movido los hilos para dar un escarmiento a su pariente ${ }^{14}$.

La defensa de Pastor se basó en descalificar a los tres testigos presentados por el conde. De José Juan, alias El Romo, afirmó que era un jornalero poco inclinado al trabajo, contrabandista de tabaco a pequeña escala, y que acostumbraba a jurar en falso; Constantino Terol era calificado de lujurioso y que se hallaba con frecuencia embriagado; del tercer testigo, Juan Bautista Senia, decía que sus rentas se hallaban desde hacía años embargadas y que, como Terol, tenía gran afición a la bebida. Según Pastor, sus declaraciones habían sido hechas por venganza: José Juan, El Romo, había sido incluido por Pastor en la leva para el ejército ${ }^{15}$ y Terol había sido instigado por éste, mientras que la declaración de Senia se basaba en una simple conversación, y que era sabido por todos que Senia se hallaba vinculado con el conde por estrechos vínculos de amistad. Era todo una «cautelosa conjuración», una calumnia urdida por el conde.

La sentencia pronunciada por la Audiencia de Valencia el 14 de octubre de 1794 fue contraria a Lumiares. La Sala del Crimen del tribunal valenciano no consideró que las expresiones de Pastor, en el caso de ser ciertas, fuesen constitutivas de delito, sino manifestaciones vagas de un hombre inconsiderado, dignas de reprimenda, pero dichas sin ánimo alguno de ejecutarlas. Las declaraciones de los testigos, a los que la Audiencia calificaba de hombres «con notables defectos», no eran convincentes y en ellas se apreciaban numerosas contradicciones, por lo que el 1 de octubre ordenó a las autoridades de Muchamiel que procedieran al encarcelamiento tanto de José Juan El Romo, como de Constantino Terol por posible perjurio. En definitiva, la Audiencia consideró infundada la acusación del conde, ordenó levantar el arresto a que estaba sometido Pastor en la ciudad de Valencia, y condenó a Lumiares al pago de las costas, a una multa de 500 pesos para penas de cámara y gastos de justicia de la Audiencia, y a abonar otros 500 pesos a Pastor en razón de daños y perjuicios, a quien debía reconocer «por hombre honrado y buen vasallo de S. M.». Dos de los testigos, José Juan, El Romo y Constantino Terol fueron condenados a 6 años de servicios en la Marina, «para el destino que fuesen útiles» por falso testimonio. El 5 de diciembre pasaba Terol a la cárcel de Alicante, y el 13 de enero de 1795 lo hacía El Romo.

14. A. H. N. Consejos leg. 22.839 Certificación del Escribano de Cámara de la Real Audiencia de Valencia D. Tomás Aguilar con referencia a Autos suscitados en ella contra Francisco Poveda sobre haber permitido Máscaras en la Universidad de San Juan, con expresión de los testigos que depusieron en el sumario en el año de 1783.

15. A. H. N. Consejos leg. 22.839 Individuos que compusieron la Junta para la leva en la Universidad de San Juan. 
El 20 de octubre la Sala acordó que su gobernador, de manera reservada, recomendase a Lumiares que no le era conveniente residir en San Juan, y «que sería muy del caso que un personaje como el conde fijase su residencia en alguna capital, o a lo menos en ciudad subalterna», y que se comportara en el futuro como correspondía a lo ilustre de su nacimiento.

El recurso ante la Audiencia no modificó la sentencia, que fue ratificada como definitiva, con pago de costas, el 23 de junio de $1795^{16}$.

Tras la decisión de la Audiencia, Lumiares recurrió en 1795 al Consejo de Castilla para que la causa fuera vista en la Sala de Justicia del alto tribunal de la monarquía, al que fueron trasladados desde Valencia los autos por orden del Consejo de 14 de abril de $1796^{17}$. Ya era por entonces una causa voluminosa, pues sumaba 830 folios.

Según los abogados del conde, haber sido tratado de calumniador suponía un ataque a su honor, «faltando al decoro y respeto debido a su nacimiento». Y para apoyar su acusación contra Pastor aportaban las declaraciones de 41 testigos, que fueron sometidas a un minucioso escrutinio por los abogados de Pastor. Al parecer, Lumiares era aficionado a juegos prohibidos, que organizaba en su casa. Dieciocho de sus testigos eran participantes asiduos, al parecer, en tales juegos, y varios de ellos compañeros en las jornadas de caza en el pago de Aguas a las que asimismo era aficionado Lumiares. Así sucedía, entre otros, con el notario de San Juan, Vicente Boix, cuyo escribiente también figuraba como testigo ${ }^{18}$; con D. Félix Ferrándiz y su cuñado, el que fuera alcalde de San Juan, Miguel Aracil, ambos amigos del conde, como también lo era Vicente Giner, acompañante suyo en las cacerías. Pero es significativo que en su práctica totalidad fueran miembros de la facción de José Llopis, que en San Juan se oponía - como se ha dicho - a la que encabezaba Pastor, y con vínculos familiares entre ellos: José Pérez de Alejandro había pleiteado con Pastor por asuntos relacionados con el reparto de aguas para riego, y por ello castigado con una fuerte multa ${ }^{19}$; Antonio Alemany seguía pleitos contra Pastor en el juzgado de San Juan; otro testigo era hermano del suegro de El Romo, y considerado tan enemigo de Pastor que había sido multado en el juzgado de aguas de Alicante por presentar un papel falso contra él; y también testificaban un primo hermano suyo y su mujer. La gran mayoría eran personas del entorno clientelar de

16. A. H. N. Consejos leg. 22.839 Sentencia de revista de la Real Audiencia de Valencia en 29 de junio de 1795. Ministros: Gobernador de la Sala del Crimen, Juan José Negrete, Manuel Mahamud, José de Villa y Torres, y Manuel de Villafañe.

17. A. H. N. Consejos leg. 22.839 Eugenio Llaguno al Obispo Gobernador del Consejo, Aranjuez 14 de abril de 1796.

18. A. H. N. Consejos leg. 22.839 Testimonio de Vicente Boix, Escribano del Juzgado de San Juan, edad de 50 años, $2 .^{\circ}$ testigo citado por Pastor.

19. A. H. N. Consejos leg. 22.839 Certificación de autos en que fueron condenados José Llopis de Onofre y José Pérez de Alejandro en el año de 1781. 
Lumiares o de su familia: Telmo Albiñana dirigía su casa; D. Teodoro Rubio era su médico y D. Vicente Mas lo era de su madre; figuraba el casero del hermano del conde, o trabajadores de sus tierras; el padrastro de su procurador, y muchos amigos íntimos, como Bautista Lledó, en cuya calesa acostumbraba a pasear el conde durante la feria de la Santa Faz, o D. Tomás Soler, quien se alojaba de continuo en casa del conde como asistente suyo. El conde había estado con anterioridad indirectamente envuelto en una causa de contrabando abierta por la Dirección de Rentas por la denuncia de Josefa Buades, estanquera de Muchamiel. Algunos de los hombres y mujeres implicados en ella, y por la que acabaron presos, también depusieron en contra de Pastor. Todas estas circunstancias restaron credibilidad a sus declaraciones.

Los abogados de Antonio Pastor solicitaron al Consejo de Castilla en sus conclusiones que fuera confirmada la sentencia de la Audiencia valenciana, que se indemnizara a su cliente con 5.000 pesos por daños y perjuicios, y se desterrase a Lumiares a 10 leguas de San Juan por falso calumniador, además de castigar al notario Vicente Boix con la pérdida de su oficio y destierro por perjurio.

Ya que tanto Lumiares como Pastor se atribuían recíprocamente delitos, y dado el volumen que había adquirido la causa, el Fiscal del Consejo, Gabriel de Achútegui, solicitó el 10 de febrero de 1797 que se pasaran los autos a un relator para que presentara un resumen de los hechos, petición que fue aceptada por el tribunal, y el 4 de mayo se citó a las partes para cotejar en su presencia el apuntamiento del relator.

El 25 de enero de 1798 fue señalada la vista y el 5 de febrero se dictó sentencia, de nuevo desfavorable para Lumiares. Se le condenaba a indemnizar a Pastor con otros 500 pesos por daños y perjuicios, y al pago al mismo Pastor de sus costas, que ascendieron, una vez tasados sus gastos, a 5.591 reales y 2 maravedíes, de los que 3.264 reales fueron honorarios pagados al estudio del abogado madrileño Miguel Ruiz ${ }^{20}$. El 3 de marzo, el conde abonó estas cantidades mediante la aportación de dos vales reales y dinero en efectivo.

20. A. H. N. Consejos leg. 22.839 Costas causadas por D. Antonio Pastor en la Instancia del Consejo y presentes Autos seguidos con el Conde de Lumiares sobre criminalidad, Madrid 10 de febrero de 1798 . 